www.nature.com/ja

\title{
In vitro antitrypanosomal activity of 12 low-molecular-weight antibiotics and observations of structure/activity relationships
}

\author{
Masato Iwatsuki ${ }^{1}$, Kazuhiko Otoguro ${ }^{1}$, Aki Ishiyama ${ }^{1}$, Miyuki Namatame ${ }^{1}$, Aki Nishihara-Tukashima ${ }^{1}$, \\ Junko Hashida $^{1}$, Takuji Nakashima ${ }^{2}$, Rokuro Masuma ${ }^{2}$, Yoko Takahashi ${ }^{2}$, Haruki Yamada ${ }^{2}$ and Satoshi Ōmura ${ }^{2}$
}

The Journal of Antibiotics (2010) 63, 619-622; doi:10.1038/ja.2010.99; published online 18 August 2010

Keywords: antitrypanosomal; low-molecular-weight antibiotics; structure/activity relationships

Human African trypanosomiasis, or Sleeping Sickness, results from infection with Trypanosoma brucei parasites transmitted by Tsetse flies of the genus Glossina. The disease is a major cause of morbidity and mortality throughout sub-Saharan Africa, wherein it occurs in epidemics, with an estimated 70 million people at risk of infection. Over the past two-three decades, recent control efforts have reduced its incidence, annual cases totaling an estimated 50000-70000. Human African trypanosomiasis has two distinct forms (gambiense and rhodesiense) depending on the parasite involved. Each form exhibits two stages dependent on whether the parasite crosses the blood/brian barrier. Without treatment, Human African trypanosomiasis is fatal, with treatment depending on the stage of the disease. Commonly used drugs for early stage disease (pentamidine and suramin) are well tolerated, relatively easy to administer and more effective. Drug for the late stage (melarsoprol, and eflornithine which is ineffective for the acute rhodesiense form), have to cross the blood/ brain barrier. They are not well tolerated and toxic (particularly melarsoprol), often causing severe or fatal side effects. They also have to be administered under costly medical supervision making them less suitable for use in Africa. Consequently, development and use of safer, more effective, easy to use and affordable drugs is urgently needed and will be a vital component in helping recent initiatives aimed at eliminating the disease as a public health problem accomplish that goal. To avoid problems faced as a consequence of expanding drug resistance, coordinated international searches are under way to discover compounds that have novel structures and modes of action. (http://www.dndi.org//).

During the course of our screening program to identify new antitrypanosomal compounds, we evaluated isolates from soil microorganisms as well as compounds lodged in the antibiotic libraries of the Kitasato Institute for Life Sciences. We have previously reported on various microbial metabolites which exhibited promising antitrypanosomal properties. ${ }^{1-3}$ We have recently investigated 12 compounds of low-molecular weight, with molecular weights ranging from 219 to 533. The compounds, all known to possess antibiotic properties, are andrastin A, 8-chloro-3', $4^{\prime}, 5,7$-tetrahydroxyisoflavone (CTI), gliotoxin, gliovirin, isochromophilone I, ochrephilone, lankacidin A, okilactomycin, piloquinone, SF2583A and B (both metabolites of Streptomyces fradiae isolated from marine environments), ${ }^{4}$ and thiolutin. In this study, we report the antitrypanosomal profiles of these 12 antibiotics (Figure 1) in comparison with those of two clinically used antitrypanosomal drugs, eflornithine and suramin. We also present some specific findings regarding structure-activity relationships.

Test compounds were obtained from the antibiotic libraries of the Kitasato Institute for Life Sciences. In vitro antitrypanosomal activities against Trypanosoma brucei brucei strain GUT at 3.1 and cytotoxicity against human diploid embryonic cell line MRC-5 were measured, as described previously. ${ }^{1}$

Table 1 shows the in vitro antitrypanosomal activities of the 12 compounds tested, as well as the two leading antitrypanosomals. Gliotoxin and thiolutin possessed extremely high antitrypanosomal properties, with the half-maximal inhibitory concentration $\left(\mathrm{IC}_{50}\right)$ values of 0.88 and $1.9 \mathrm{ng} \mathrm{ml}^{-1}$ respectively. These compounds were 800-2600-fold more potent than eflornithine or suramin. Lankacidin A, okilactomycin and piloquinone were 19-38-fold less active than gliotoxin, showing $\mathrm{IC}_{50}$ values of $17-33 \mathrm{ng} \mathrm{ml}^{-1}$. Gliovirin was about 100 -fold less active than gliotoxin showing an $\mathrm{IC}_{50}$ value of approximately

${ }^{1}$ Research Center for Tropical Diseases, Kitasato Institute for Life Sciences, Kitasato University, Tokyo, Japan and ${ }^{2}$ Kitasato Institute for Life Sciences, Graduate School of Infection Control Sciences, Kitasato University, Tokyo, Japan

Correspondence: Dr K Otoguro or Professor S Ōmura, Research Center for Tropical Diseases, Kitasato Institute for Life Sciences, Graduate School of Infection Control Sciences, Kitasato University, 5-9-1 Shirokane, Minato-ku, Tokyo 108-8641, Japan.

E-mail: otoguro@lisci.kitasato-u.ac.jp or omuras@insti.kitasato-u.ac.jp

Received 16 June 2010; revised 19 July 2010; accepted 21 July 2010; published online 18 August 2010 


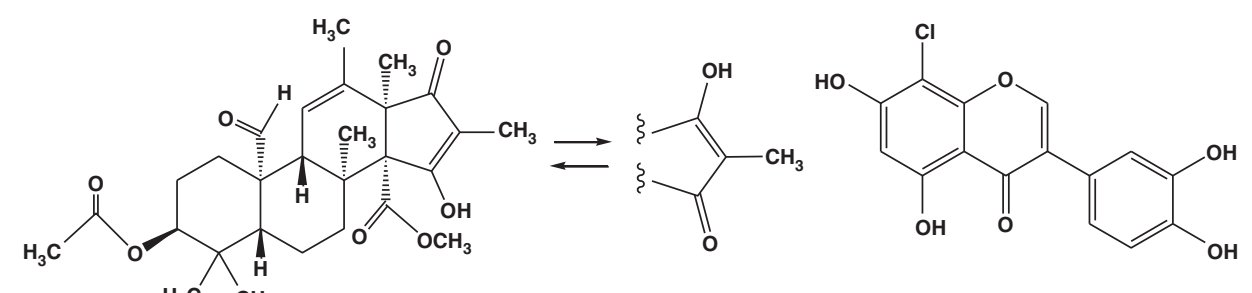

Andrastin A

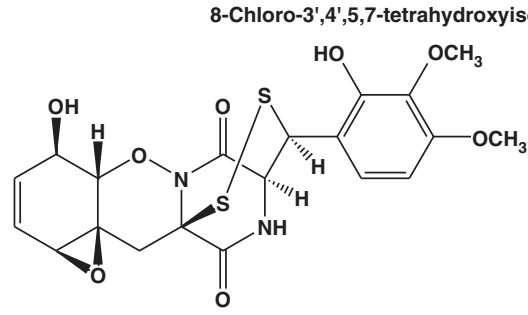<smiles>[R]C1=C2C=C(/C=C/C(C)=C/C(C)CC)OC=C2C2C(C(C)=O)C(=O)OC2(C)C1=O</smiles>

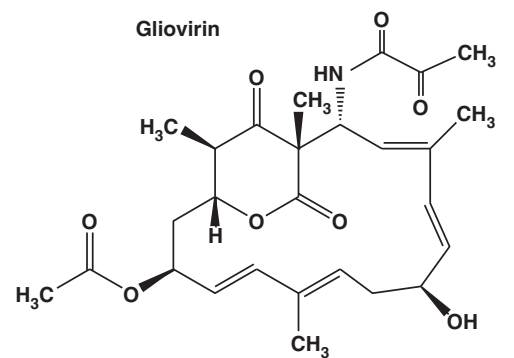

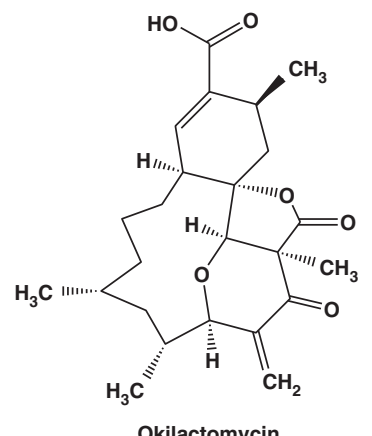<smiles>Cc1c(C(=O)CCC(C)O)cc2c(c1O)C(=O)C(=O)c1c(O)cccc1-2</smiles>

Lankacidin A<smiles>Pc1ncoc1-c1c[nH]c2ccccc12</smiles>

$\mathbf{R}$ SF2583A Cl<smiles>CC(=O)Nc1c2sscc-2n(C)c1=O</smiles>

Thiolutin

Figure 1 Structures of antitrypanosomal low-molecularweight antibiotics.

$90 \mathrm{ng} \mathrm{ml}^{-1}$. CTI, SF2583A and isochromophilone I were 240-350-fold less active than gliotoxin showing $\mathrm{IC}_{50}$ values of $210-310 \mathrm{ng} \mathrm{ml}^{-1}$. Andrastin $\mathrm{A}$ and ochrephilone produced $\mathrm{IC}_{50}$ values around $1 \mu \mathrm{g} \mathrm{ml}^{-1}$, significantly higher than eflornithine and suramin, whereas SF2583B appears to have no antitrypanosomal activity.

The in vitro cytotoxicities of all compounds tested are also presented in Table 1. Gliotoxin and thiolutin proved extremely toxic against MRC-5 cells, with $\mathrm{IC}_{50}$ values of $16-21 \mathrm{ng} \mathrm{ml}^{-1}$. Okilactomycin and piloquinone were also revealed to be cytotoxic, demonstrating $\mathrm{IC}_{50}$ values of $310-630 \mathrm{ng} \mathrm{ml}^{-1}$. Gliovirin and lankacidin A also showed a relatively cytotoxic characteristic, demonstrating $\mathrm{IC}_{50}$ values of $1.4-3.6 \mu \mathrm{g} \mathrm{ml}^{-1}$, whereas andrastin $\mathrm{A}$, CTI, isochromophilone I, ochrephilone and SF2583A had $\mathrm{IC}_{50}$ values of $>10 \mu \mathrm{g} \mathrm{ml}^{-1}$, exhibiting very low cytotoxicity, but still far more than the currently used suramin and eflornithine.

For a more appropriate and relevant comparison of the suitability of these compounds for possible development as human medicaments, we devised a selectivity index (SI). The SI for was determined by ( $\mathrm{IC}_{50}$ for the MRC-5 cells)/antitrypanosomal activity ( $\mathrm{IC}_{50}$ for the GUT at 3.1 strain)) as presented in Table 1. Among the tested compounds, lankacidin A and SF2583A showed a high SI, 109 and 106 respectively, far higher than that of either eflornithine or suramin. CTI and isochromophilone I, with a SI of 45 and 61 respectively, were similar to those of both currently used antitrypanosomals. Piloquinone $(\mathrm{SI}=30)$ also exhibited a comparatively good result. The other compounds, andrastin A, gliotoxin, gliovirin, ochrephilone, okilactomycin and thiolutin showed a SI significantly lower than the existing drugs tested.

Our results drew attention to the fact that SF2583B showed no antitrypanosomal activity whatsoever, whereas SF2583A possessed significant activity. Similarly, ochrephilone showed only a moderate antitrypanosomal impact, whereas isochromophilone I proved considerably more effective. These observations provide significant insight into the structure-activity relationship connected with antitrypanosomal activity. SF2583B lacks the chlorine atom at the C-2 position of the oxazole moiety of SF2583A, rendering SF2583B > 54-fold 
Table 1 In vitro antitrypanosomal activity against Trypanosoma brucei brucei GUTat 3.1 and cytotoxicity in MRC-5 cells of some low-molecular-weight antibiotics and two commonly used antitrypanosomal drugs

\begin{tabular}{|c|c|c|c|}
\hline \multirow[b]{3}{*}{ Compound } & \multicolumn{2}{|l|}{$I_{50}\left(n g m I^{-1}\right)$} & \multirow{3}{*}{$\begin{array}{c}\text { Selectivity } \\
\text { index (SI) } \\
\text { MRC-5/GUTat } 3.1\end{array}$} \\
\hline & Antitrypanosomal activity & Cytotoxicity & \\
\hline & GUTat 3.1 & $M R C-5$ & \\
\hline Andrastin A & 700 & 14110 & 20 \\
\hline CTI & 310 & 13980 & 45 \\
\hline Gliotoxin & 0.88 & 16 & 18 \\
\hline Gliovirin & 91 & 1410 & 16 \\
\hline Isochromophilone I & 210 & 12740 & 61 \\
\hline Ochrephilone & 1020 & 10290 & 10 \\
\hline Lankacidin A & 33 & 3600 & 109 \\
\hline Okilactomycin & 17 & 310 & 18 \\
\hline Piloquinone & 21 & 630 & 30 \\
\hline SF2583A & 230 & 24470 & 106 \\
\hline SF2583B & $>12500$ & ND & - \\
\hline Thiolutin & 1.9 & 21 & 11 \\
\hline Eflornithine & 2270 & $>100000$ & $>44$ \\
\hline Suramin & 1580 & $>100000$ & $>63$ \\
\hline
\end{tabular}

Abbreviations: CTI, 8-Chloro-3',4',5,7-tetrahydroxyisoflavone; ND, not determined.

less active than SF2583A. Recently, Nakashima et al. ${ }^{4}$ reported that SF2583A (12815A) possesses potent antityrosinase activity, but SF2583B (12815B) does not. They suggested that the chlorine atom in SF2583A plays an important role in bestowing the antityrosinase activity. This would appear to also be the case with respect to antitrypanosomal activity. Similarly, ochrephilone lacks a chlorine atom at the C-4 position, wherein it is found in isochromophilone I, effectively rendering ochrephilone fivefold less active against trypanosomes. Our data therefore suggest that the chlorine atoms present in SF2583A and isochromophilone I has a significant role in the creation of antitrypanosomal activity.

Further studies are necessary for extensive structure in vitro antitrypanosomal activity evaluation of SF2583A and isochromophilonesrelated compounds.

With respect to the characteristics of the compounds tested, andrastin A is a meroterpeniod compound. Gliotoxin is a epipolythiodiketopiperazine and is known to have antifungal, antibacterial, antiviral and antitumor properties. ${ }^{5}$ We have previously reported that andrastin A and gliotoxin are both inhibitors of protein farnesyltransferase from human cell THP-1. ${ }^{6,7}$ protein farnesyltransferase is one of the key molecular targets for antitrypanosomal agents, as determined by the UN's Special Programme for Research \& Training in Tropical Diseases (TDR) (http://tdrtargets.org//). Ali et al. ${ }^{8}$ previously reported that manumycin A, a known microbial protein farnesyltransferase inhibitor, also showed an inhibitory effect on Trypanosome development in vitro by inhibiting Trypanosomal protein farnesyltransferase. Lankacidin A (bundlin B), a veterinary medicine, is a 17 -membered ring macrolide compound and is reported to have antibacterial activity, ${ }^{9}$ its mode of action being via inhibition of protein synthesis. ${ }^{10}$ Gliovirin is an epipolythiodiketopiperazine and is reported to have antianaerobic bacteria and antifungal activity. ${ }^{11}$ Recently, Rether et. al. ${ }^{12}$ reported its mode of action is through suppression of tumor necrosis factor- $\alpha$ synthesis by inhibition of the activation of extracellular signal-regulated kinase. Gliotoxin and gliovirin possess an -SS- bridge between the $\alpha$-positions of the cyclic dipeptide and the $\alpha$ - and $\beta$-positions of the amino acid residues, respectively (Figure 1). It is significant that both compounds containing the -SS- bridge show potent antitrypanosomal activity. We previously reported that CTI has antioxidant and antitumor activity, ${ }^{13}$ though the mode of action is not clearly understood. However, a related common isoflavone, genistein, is reported to have antitrypanosomal activity, and its mode of action is inhibition of protein synthesis, primarily serine and threonine phosphorylation. ${ }^{14}$ Okilactomycin is a polyketide compound reported to have antitumor and weak antibacterial activity. ${ }^{15}$ Recently, Zhang et al. ${ }^{16}$ confirmed that its mode of action in bacterial cells is via inhibition of RNA synthesis. Piloquinone is a phenanthrenequinone and exhibits antibacterial activity, ${ }^{17}$ although the mode of action is not known. However, a related antibiotic, haloquinone, disrupts DNA synthesis in bacterial cells. ${ }^{18}$ Thiolutin is a dithiolopyrrolone, which demonstrates antibacterial, antifungal and antiameboid parasite activity. ${ }^{19}$ Its mode of action in yeast is through inhibition of RNA polymerase. $^{20}$ SF2583A (streptochlorin, 12815A) and SF2583 B (12815B) are oxazolyl indole compounds with weak antinematoda, antitumor and antiangiogenic activity, and they also inhibit tumor necrosis factor- $\alpha$-induced necrosis factor- $\kappa \mathrm{B}$ activity and tyrosinase in mushroom and mammalian cells, ${ }^{4,21,22}$ although the action mechanism remains unclear. Isochromophilone I and ochrephilone are azaphilone antibiotics. We previously reported that both compounds are inhibitors of gp120-CD4 binding, ${ }^{23}$ though the mode of action is not fully determined. The reported action mechanisms of andrastin A, gliotoxin, gliovirin, lankacidin A, okilactomycin and thiolutin may be involved in determining their impact against Trypanosomes.

The discovery of the antitrypanosomal activities of andrastin A, CTI, gliotoxin, gliovirin, isochromophilone I, ochrephilone, lankacidin A, okilactomycin, piloquinone, SF2583A and thiolutin are novel and our data constitute the first report of such properties.

The above results reveal that several low-molecular-weight antibiotics are promising 'drug-like' lead compounds for possible development into novel antitrypanosomal drugs. Our observations on specific structure/activity relationships may also prove of significant use in the future rational design of new and novel antitrypanosomals. Further studies of the antitrypanosomal and other biological activities of these antibiotics are in progress.

\section{ACKNOWLEDGEMENTS}

This work was supported, in part, by funds from the Drugs for Neglected Diseases initiative (DNDi), Quality Assurance Framework of Higher Education from the Ministry of Education, Culture, Sports, Science and Technology, Japan (MEXT), and the All Kitasato Project Study (AKPS). We are grateful to Ms $\mathrm{H}$ Sekiguchi and Mr T Furusawa for their technical assistance.

1 Otoguro, K. et al. Selective and potent in vitro antitrypanosomal activities of 10 microbial metabolites. J. Antibiot. 61, 372-378 (2008).

2 Ishiyama, A. et al. In vitro and in vivo antitrypanosomal activities of two microbial metabolites, KS-505a and Alazopeptin. J. Antibiot. 61, 627-632 (2008).

3 Ishiyama, A. et al. In vitro and in vivo antitrypanosomal activities of three peptide antibiotics: Leucinostatin A and B, alamethicin I and tsushimycin. J. Antibiot. 62, 303-308 (2009).

4 Nakashima, T. et al. Physiochemical characters of a tyrosinase inhibitor produced by Streptomyces roseolilacinus NBRC 12815. Biol. Pharm. Bull. 32, 832-836 (2009).

5 Cole, R. J. \& Cox, R. H. In Handbook of Toxic Fungal Metabolites, Academic Press: New York, 1981; Chapter 11, pp 569-645.

6 Ōmura, S. et al. Andrastins A C , new protein farnesyltransferase inhibitors produced by Penicillium sp. FO-3929. I. Producing strain, fermentation, isolation, and biological activities. J. Antibiot. 49, 414-417 (1996).

7 Van Der Pyl, D. et al. Inhibition of protein farnesyltransferase by gliotoxin and acetylgliotoxin. J. Antibiot. 45, 1802-1805 (1992). 
8 Ali, B. R. S., Pal, A., Croft, S. L., Taylor, R. J. K \& Field, M K. The farnesyltransferase inhibitor manumycin is a novel trypanocide with a complex mode of action, including major effects on mitochondria. Mol. Biochem. Parasitol. 104, 67-80 (1999).

9 Harada, S., Higashide, E., Fugono, T. \& Kishi, T. Isolation and structures of T-2636 antibiotics. Tetrahedron Lett. 27, 2239-2244 (1969).

10 Tsuchiya, K., Yamazaki, T., Takeuchi, Y. \& Oishi, T. Studies on T-2636 antibiotics. IV In vitro and in vivo antibacterial activity of T-2636 antibiotics. J. Antibiot. 24, 29-41 (1971).

11 Stipanovic, R. D. \& Howell, C. R. The structure of gliovirin, a new antibiotic from Gliocladium virens. J. Antibiot. 35, 1326-1330 (1982).

12 Rether, J., Serwe, A., Anke, T. \& Erkel, G. Inhibition of inducible tumor necrosis factoralpha expression by the fungal epipolythiodiketopiperazine, gliovirin. Biol. Chem. 388, 627-637 (2007).

13 Komiyama, K. et al. Isolation of isoflavonoids possessing antioxidant activity from the fermentation broth of Streptomyces sp. J. Antibiot. 42, 1344-1348 (1989).

14 Gale Jr, M., Carter, V. \& Parsons, M. Cell cycle-specific induction of an 89 kDa serine/ threonine protein kinase activity in Trypanosoma brucei. J. Cell. Sci. 107, 1825-1832 (1994).

15 Imai, H. et al. Okilactomycin, a novel antibiotic produced by Streptomyces species. I. Taxonomy, fermentation, isolation and characterization. J. Antibiot. 40, 1475-1482 (1987).
16 Zhang, C. et al. Discovery of okilactomycin and congeners from Streptomyces scabrisporus by antisense differential sensitivity assay targeting ribosomal protein S4. J. Antibiot. 62, 55-61 (2009).

17 Johnson, B. C., Cohen, P., Polonsky, J. \& Lederer, E. Piloquinone, a new phenanthrene- 0 quinone isolated from the mycelium of Streptomycespilosus. Nature 199, 285-286 (1963).

18 Ewersmeyer-Wenk, B., Zahner, H., Krone, B. \& Zeeck, A. Metabolic products of microorganisms. 207. Halaquinone, a new antibiotic active halobacteria. I. Isolation, characterization and biological properties. J. Antibiot. 34, 1531-1537 (1981).

19 Celmer, W. D. \& Solomons, I.. A. The structures of thiolutin and aureothricin, antibiotics containing a unique pyrrolinonodithiole nucleus. J. Am. Chem. Soc. 77, 2861-2865 (1955).

20 Tipper, D. J. Inhibition of yeast ribonucleic acid polymerase by thiolutin. J. Bacteriol. 116, 245-256 (1973).

21 Watabe, H. et al. A new antibiotic SF2583A, 4-chloro-5-(3'-indolyl)oxazole, produced by Streptomyces. Sci. Reports of Meiji Seika Kaisha 27, 55-62 (1988).

22 Choi, I. K., Shin, H. J., Lee, H. S. \& Kwon, H. J. Streptochlorin, a marine natural product, inhibits NF-кB activation and suppresses angiogenesis in vitro. J. Microbiol. Biotechnol. 17, 1338-1343 (2007).

23 Ōmura, S., Tanaka, H., Matsuzaki, K., Ikeda, H. \& Masuma, R. Isochromophilons I, II, novel inhibitors against gp120-CD4 binding from Penicillium sp. J. Antibiot. 46, 1908-1911 (1993). 